\title{
Optimised Design of Permanent Magnet Assisted Synchronous Reluctance Machines for Household Appliances
}

\author{
Michele Degano, Member, IEEE, Mukhammed Murataliyev, Member, IEEE, Wang Shuo, Member, IEEE, Davide \\ Barater, Member, IEEE, Giampaolo Buticchi, Member, IEEE, Werner Jara, Member IEEE, Nicola Bianchi, Senior \\ Member, IEEE, Michael Galea, Senior Member, IEEE, Chris Gerada, Senior Member, IEEE.
}

\begin{abstract}
This paper is focused on the design, optimisation and control of a permanent magnet assisted synchronous reluctance machine (PMaSynRel) for low cost high efficiency household appliances, in particular a motor for washing machine. The design and optimisation of the motor aims at maximising the torque produced and power factor, while minimise torque oscillations and the losses, thus improving the efficiency. A campaign of tests has been carried out on the prototype of the optimised machine, comparing finite element results and experimental measurements as a validation of the proposed design. In addition, torque ripple measurements are confirming that the solution proposed is meeting the optimisation design targets. The outcomes of this project are demonstrating that PMaSynRel drives are a suitable candidate for white goods sector, and that the proposed design is able to boost the performance and efficiency class with respect to the state-of-the-art solutions.
\end{abstract}

Index Terms - Permanent Magnet Assisted Synchronous Reluctance, Machine Design, Motor Optimization, Efficiency Improvement, Washing Machines.

\section{INTRODUCTION}

The continuous increase of electrical energy demand compels a significant effort in the direction of reducing environment pollution and greenhouse gases [1]. Therefore, the efficiency improvement of electric motors and drives, adopted in many application fields, is of paramount importance [2]. New standards on rotating electrical machines are becoming more demanding than in the past, especially in terms of efficiency and cost [3]. Premium/IE3 efficiency class motors are now mandatory in North America and other countries. SuperPremium/IE4 and Ultra-premium/IE5 efficiency classes are to be defined in the 2nd Edition of the IEC3 60034-30 standard. For line-start fixed-speed applications, Super-Premium/IE4class line-start permanent magnet (PM) motors and squirrelcage induction motors are recent entrances in the industrial motor market [1]. For variable-speed applications, IE4-class synchronous reluctance motors are also a recent entrance in the market. An important measure for wide market acceptance of high efficiency motors is the availability of harmonized standards, dealing with motor performance testing, efficiency classification, and display of ratings [4]. This also applies to variable speed drives (VSDs). In the United States, Premium/IE3 motors have been mandatory since 2011. In China and EU countries, High-Efficiency/IE2 motors have been mandatory since 2011, while Premium/IE3 motors since 2015 [5]. So far, household appliances, such as washing machines, dishwashers, dryers and vacuum cleaners, have been mainly powered by Universal Motors (UMs) [6], which are still widely used covering the $80 \%$ of the worldwide market. Although during the last ten years, many other types of electric motors have been considered as alternatives, UMs are still surviving thanks to their advantages such as good power versus size ratio, simplicity of control and regulation over a wide speed range, including low cost of the simple drive [7]. On the other side, they suffer from low efficiency values compared to other kinds of motors and from maintenance issues due to the presence of commutator and brushes [7], [8]. It is clear that in the next few years, also low power household appliances will have to satisfy higher efficiency requirements. This will lead to a change in the motor topologies applied for washing machines applications as well. Squirrel Cage Induction Machines (SCIM) are another dominant motor type in the house hold appliances market [9], [10]. SCIMs are suitable for a wide speed range of operation $(15000-18000 \mathrm{rpm})$ and they are considered a rugged motor topology and thanks to their refined manufacturability they are considered to be a cost-effective solution. However, because of the losses excited by the rotor cage and iron laminations, their maximum efficiency is ranging from $\sim 52$ to $75 \%$, depending on the operating condition [9], [11]. As these machines' frame size is relatively small, these efficiency values are considered acceptable. Presently, the Synchronous Reluctance (SynRel) motors appear to be one of the attractive emerging electrical machines. They have been proven suitable for industrial applications [12]-[13] and for lightweight vehicles traction [14]-[15]. These motors present excellent features such as a robust structure and very high-speed capabilities. The absence of excitation winding, in the rotor, and low back electro motive force lead to a safe behaviour in case of inverter failure and higher efficiency [16]. On the contrary, the well-known drawbacks of reluctance machines are the poor power factor and the non-negligible torque ripple [17]. The optimization of the machines' geometry can mitigate these drawbacks and maximize the motor performance. Furthermore, the power factor and the machine torque density can be improved with addition of small quantities of rare-earth magnets, or lower cost ferrite magnets resulting in a Permanent Magnet assisted Synchronous Reluctance (PMaSynRel) configuration [18][19]. With respect to induction machines with the same frame size, the PMaSynRel machines exhibit a higher torque density and efficiency, over a wider operating speed range [4], [5], [18]. 
Other methods to improve the power factor of SynRel machines, without using permanent magnets, have been shown in [20], where the feasibility of a ribless solution, embedding resin within the rotor structure, has been presented and validated. However, that technology still presents some limitations in terms of full operating capability, as well as retention limitations due to mechanical and thermal challenges.

SynRel machines with ferrite injection have also been presented for washing machine applications in different research works [10], [20], highlighting higher efficiency and relatively cheap price, with respect to SCIMs. The use of ferrite magnets is not significantly affecting the cost of the motor because of the low material price, about $3.28 \$ / \mathrm{kg}$ [1].

In [21], the PMaSynRel machine with concentrated winding having an unconventional for a house appliances 9slot/8pole combination was presented, however the $\mathrm{NdFeB}$ rare earth magnets were used, hence increasing component price. In [10], the performance of the 4-pole SynRel machine with ferrite injection for household application was investigated, various advantages over conventional SynRel machines were highlighted, including a constant power operation capability.

This paper describes the complete design process for a high efficiency PMaSynRel for washing machine applications. The first part describes the design and optimisation of a PMaSynRel motor, with the aim of improving the torque capability, maximise the power factor and smooth the torque oscillations. The results of the optimisation are presented, and the most suitable machine selected from the feasible solutions along the Pareto front. The magnetic model is then used to control the machine through the drive, by implementing an MTPA control strategy. In the second part, the validation of the optimised machine design is assessed by experimental measurement for different speeds and operating conditions, showing the advantages of the design proposed.

\section{Motor DESIGN AND OPTIMIZATION}

The PMaSynRel machine has been designed with the aim to meet the torque and power performance for household applications, over a wide speed range of operation, considering the specifications reported in Table I. As an improvement of the state of the art, the novel design technique of the PMaSynRel motor has been used to ensure that the design can satisfy the requirements pushing the efficiency per volume to their limits.

Table I. Design requirements

\begin{tabular}{ccc}
\hline \hline Symbol & Parameter & Quantity \\
\hline$T$ & Rated Torque & $>1 \mathrm{Nm}$ \\
$n_{b}$ & Base speed & $5200 \mathrm{rpm}$ \\
$T_{\Delta}$ & Torque ripple & $<15 \%$ \\
$P$ & Rated Power & $600 \mathrm{~W}$ \\
$I_{r m s}$ & Phase Current & $3.5 \mathrm{~A}$ \\
$V_{r m s}$ & Phase Voltage & $120 \mathrm{~V}$ \\
\hline Constant power speed range & $5000-16000 \mathrm{rpm}$
\end{tabular}

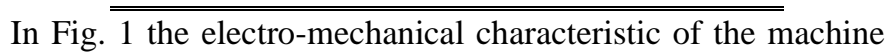
as per requirements is shown. The rated torque is $1 \mathrm{Nm}$ at base

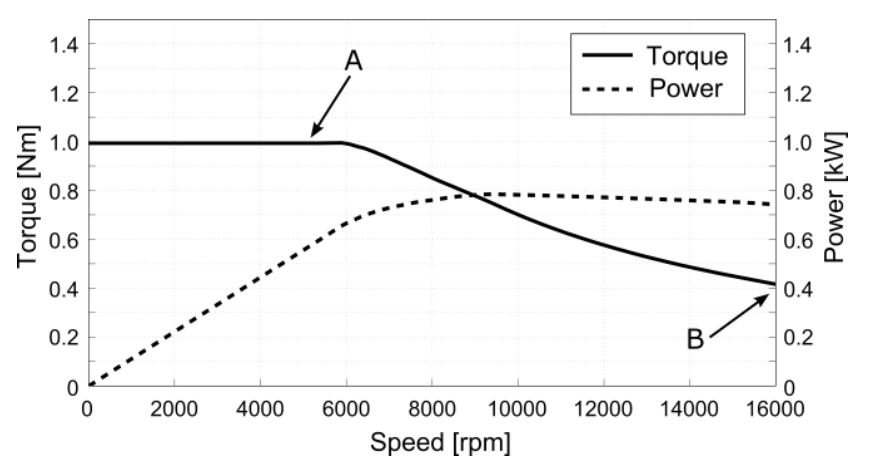

Fig. 1: Electro-mechanical characteristic: torque and power profile over the operating speed range.

speed of $5200 \mathrm{rpm}$, which is highlighted as "A". The designed machine should operate over a wide constant power speed range, from $5200 \mathrm{rpm}$ to $16000 \mathrm{rpm}$ "B", to deliver a torque of $0.4 \mathrm{Nm}$ at the maximum speed.

\section{A. Preliminary design assumptions and constraints}

In Fig. 2 a 2D sketch of stator and rotor is presented. The design presents a semi closed slotted stator (24-slots), with a geometry that is constrained by the same outer and inner stator diameter as a commercial reference induction motor, for washing machine application, to maintain the same overall volume [9], [11]. Because of the high maximum speed and the limited switching frequencies of the cost-effective commercial drives, usually between $10 \mathrm{kHz}$ to $16 \mathrm{kHz}$, a 4-pole rotor is chosen to have a compatible fundamental frequency, in this case $533.33 \mathrm{~Hz}$. For high speed machines, the centrifugal forces acting on the rotor, even if in this case the radius is relatively small, can lead to high mechanical stress. A critical speed of $18000 \mathrm{rpm}$ has been selected to ensure a safety factor over the operational speed range. The iron ribs dimensions were determined through a mechanical model to obtain a robust rotor and preserve the structure to expand under centrifugal forces. The mechanical stresses of the final geometry have been checked by means of 2D finite element analysis (FEA), considering a safety factor of 2, meaning that the maximum yield stress on the rotor structure lower than half the material limit (400MPa for a silicon steel M470-35A lamination) at any

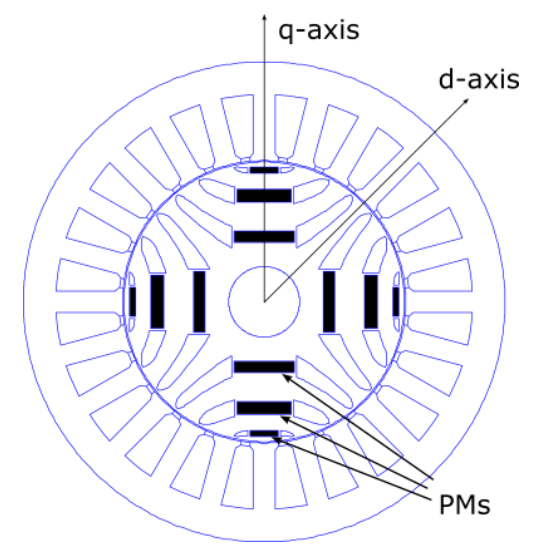

Fig. 2: 2D sketch of a ferrite assisted synchronous reluctance machine preliminary designed to meet the torque specification (before optimisation). 
point of its structure. This specific material grade has been selected to match the one use in induction motors for the same application. Other laminations with lower [21] or higher specific loss and mechanical characteristic could also be used, depending on the target cost. To the purpose of this research study, to validate the concept proposed, the M470-35A is used.

From Fig. 2 it can be noted that the rotor presents three flux barriers per pole, with the central parts of the barriers filled with ferrite permanent magnet, having the function of assisting the saturation of the radial and tangential iron ribs.

The introduction of permanent magnets in the rotor flux barriers, even a small amount, is beneficial for the improvement of the power factor as well as for the constant power speed range [22], [23]. The material used is a low-grade Ferrite (remanence flux density $0.4 T @ 20^{\circ} \mathrm{C}$, knee flux density $0.1 T$ @ $20^{\circ} \mathrm{C}$, recoil permeability 1.05 , density $4800 \mathrm{~kg} / \mathrm{m}^{3}$ ).

The application allows only natural cooling through the housing, therefore a limit to the peak current density in the slot is set preliminarily to $J_{M A X}=4 A_{r m s} / \mathrm{mm}^{2}$ to allow transient overload operations. A standard three-phase winding is considered with integral pitch. The slot fill factor is conservatively assumed to be $k_{\text {fil }}=0.4$.

\section{B. Electrical machine design}

Based on the design constrains and the design requirements reported in Table I and II, respectively, the preliminary sizing has been carried out using the analytical model presented in [24]. This is derived from a well-known $d-q$ frame torque equation:

$$
T=1.5 p\left[\left(L_{d}-L_{q}\right) i_{d} i_{q}+\lambda_{p m} i_{d}\right]
$$

Where $p$ represents the number of pole pairs, $L_{d}$ and $L_{q}$ are the direct and quadrature inductances, respectively; and $i_{d}, i_{q}$ are the direct and quadrature currents flowing in the stator windings. The main sizing equation for reluctance machines can be derived as (2):

$$
D_{r o}=\sqrt{\frac{T_{e m} \gamma \mu_{0} q K_{d m} \sqrt{\xi}}{B_{1 d}^{2} \pi g \sqrt{1+\left(\frac{1}{2 \xi-1}\right)^{2} \xi}}}
$$

Where $D_{r o}$ is the rotor outer diameter, $T_{e m}$ is the required electromagnetic torque, $q$ is the number of slots per pole per phase, $g$ is the air gap length, $\mu_{0}$ is the relative permeability of air, $B_{I d}$ is the fundamental component of $d$ excited axis and $\xi$ is the saliency ratio. $K_{d m}$ is the $d$-axis magnetizing coefficient, which is normally equals to $\sim 0.85$ for axially laminated anisotropic rotors [24]. Where stack aspect ratio is defined as:

$$
\gamma=\frac{L_{s t k}}{D_{r o}}
$$

Where $L_{\text {stk }}$ is the active stack length.

As it was discussed in [24] equation (2) accounts only for pure reluctance component considering the anisotropy of rotor, the excitation component of torque can be determined using the PM flux component (1).
Table II. Design parameters

\begin{tabular}{ccc}
\hline \hline Symbol & Parameter & Quantity \\
\hline$J_{\text {max }}$ & Peak current density & $4 \mathrm{~A}_{\mathrm{rms}} / \mathrm{mm}^{2}$ \\
$k_{\text {fill }}$ & Slot fill factor & 0.4 \\
$Q_{s}$ & Number of slots & 24 \\
$2 p$ & Pole numbers & 4 \\
$m$ & Number phases & 3 \\
$g$ & Air gap & $0.35 \mathrm{~mm}$ \\
$k$ & Number of barriers & 3 \\
\hline \hline Table III. Main machine geometrical parameters \\
\hline \hline Symbol & Parameter & Quantity \\
\hline$D_{r o}$ & Rotor outer diameter & $59.4 \mathrm{~mm}$ \\
$L_{s t k}$ & Stack length & $48 \mathrm{~mm}$ \\
$D_{s o}$ & Stator outer diameter & $102 \mathrm{~mm}$ \\
$N_{s}$ & Number of turns per phase & 144 \\
\hline \hline
\end{tabular}

The general equation of PM flux is (4):

$$
\lambda_{p m}=B_{0} L \tau_{p}
$$

Where $B_{1 o}$ is the fundamental component of the no-load flux density, and $\tau_{p}$ is the pole pitch. The preliminary sizing method adopted is summarised in the workflow shown in Fig. 3.

The process begins with a set of initial data and assignment of the key parameters. The predesign input targets are the desired rated output torque, while the predefined data and constraints are reported in Table II and Table III. Step 2 includes an initial assumption of the saliency, which is usually within a range $3 \leq$ $\xi \leq 10$; using equation (2) the rotor size can be estimated.

The analytical method includes the air gap function approach [25] and saturation coefficients [24] and is used to analyze the rotor geometry based on the predefined parameters, which are number of barriers $k$ and the magnetic insulation ratio $k_{\text {air }}$ equal to $\sim 0.36$. These are used to accurately estimate the saliency ratio $\xi$ as well as $L_{d}$ and $L_{q}$.

The general torque equation (1) can be used to estimate the torque of the initially sized machine geometry. Based on this the machine rotor diameter can be refined by adjusting either rotor geometrical parameters $k, k_{a i r}$ or main rotor diameter $D_{r o}$.

Regarding the definition of the airgap, one could highlight how such a small airgap can be achieved when considering an

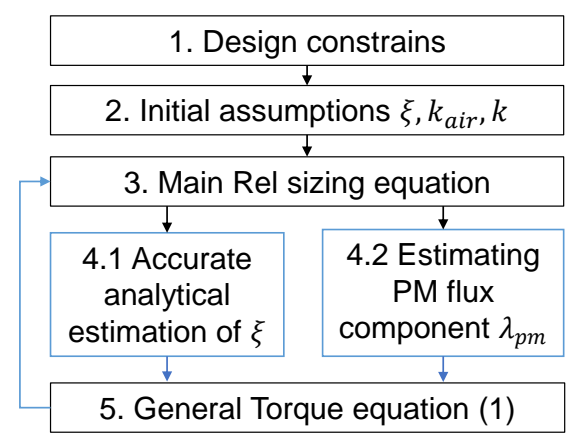

Fig. 3: PMaSynRel analytical sizing workflow. 
application defined as a low value high volume manufacturing. The airgap is for sure a parameter that has a strong impact on the motor magnetic performance. In [26] a high speed (50000 rpm) 4 pole SynRel motor, for a different application, is reporting an airgap of $0.25 \mathrm{~mm}$, and conducting a sensitivity analysis where the airgap is varied from $0.1 \mathrm{~mm}$ to $0.4 \mathrm{~mm}$, showing the torque decay for larger airgaps. Other works for higher speed motors are considering airgaps of $0.3 \mathrm{~mm}$ [27]. Even though the work carried out in this paper is a research development, it is worth to highlight that this solution might not yet be mature for mass production, as a small airgap might result in a higher manufacturing cost. However, it is not uncommon to see motors with $0.4-0.5 \mathrm{~mm}$ for household appliances and even smaller airgaps are feasible as reported in literature.

For the sake of clarity, and to show how the airgap impact the machine's torque production, a sensitivity analysis is offered for airgaps from $0.3 \mathrm{~mm}$ to $0.45 \mathrm{~mm}$, by simply reducing the rotor dimensions, while considering the same stator. In Fig. 4 , the static torque for different airgap dimensions is shown for a peak phase current of 4.6A. It can be noted how the maximum torque production is reduced for higher airgaps, almost $24 \%$ when the airgap is increased from the selected $0.35 \mathrm{~mm}$ (continuous line) to $0.45 \mathrm{~mm}$ (dotted line). Also, the current angle corresponding to the maximum torque, highlighted by the red dot representing the MTPA, is varying with the airgap. For any specific airgap, the rotor parameters, such as flux barrier angles and flux barriers thickness will require optimization, as described in the following section $\mathrm{C}$, for an airgap of $0.35 \mathrm{~mm}$.

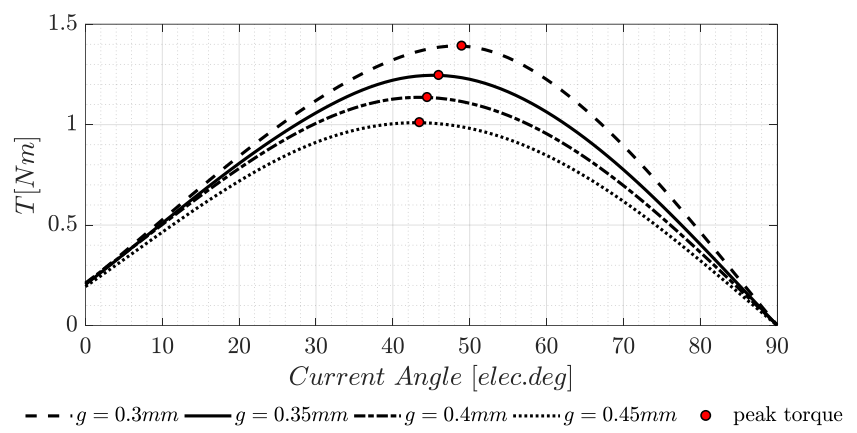

Fig. 4: Torque vs current phase angle for different air gap values at $4.6 \mathrm{~A}_{\text {peak }}$ phase current.

\section{Electrical machine optimization}

From the preliminary sizing described in section $\mathrm{B}$, a design refinement stage is introduce in order to optimise three key objective functions: maximize the torque production with the fixed machine envelope, minimize losses and torque ripple.

For this purpose, a Multi Objective Genetic Algorithm (MOGA-II) has been linked with an automatic drawing and solving procedure, implemented in Matlab, to run the finite element software FEMM 4.2. The optimisation was focused on the anisotropic structure of the rotor using the approach described in [18], as well as in the definition of the optimal stator geometry.
The software used is ModeFrontier, which is a flexible tool that integrates several genetic algorithms and can simply connect different software packages [28].

The FE-based design optimization workflow is shown in Fig. 5. The initial Design of Experiments (DOE) table used to start the search has been defined by a Sobol sequence. The number of individuals for each generation has been set to 60 and a maximum of 40 generations has been considered, leading to a total of 2400 functional evaluations. The variables of the optimization were the barrier angles, insulation ratio (eq. 5) and stator slot geometry as shown in Fig. 6. The parametrisation used to draw the rotor geometry is a combination of Joukowski's flow equations [13] with a dedicated central slot in each flux barrier for the permanent magnet insertion.

The input variables considered for the optimization of both stator and rotor structure are reported in Table IV, together with their variation boundaries.

A major constraint on the optimization was to keep the main machine envelope fixed, as previously reported in Table III.

For a reluctance machine the insulation ratio is defined based on the air portions in each barrier; in this PMaSynRel case this is considered as the PM portions with respect to the iron thickness, hence this parameter is defined as (5):

$$
k_{\text {air }}=\frac{2 \sum h c_{k}}{D_{\text {ro }}-D_{\text {sh }}}
$$

Where $D_{s h}$ is the shaft diameter and $h c_{k}$ is the $k^{\text {th }}$ barrier thickness as shown in Fig. 6.

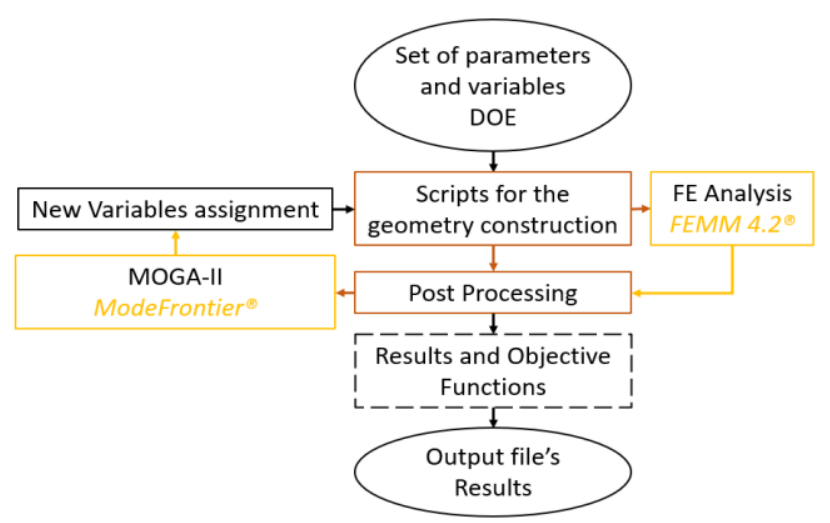

Fig. 5: Optimisation process workflow.

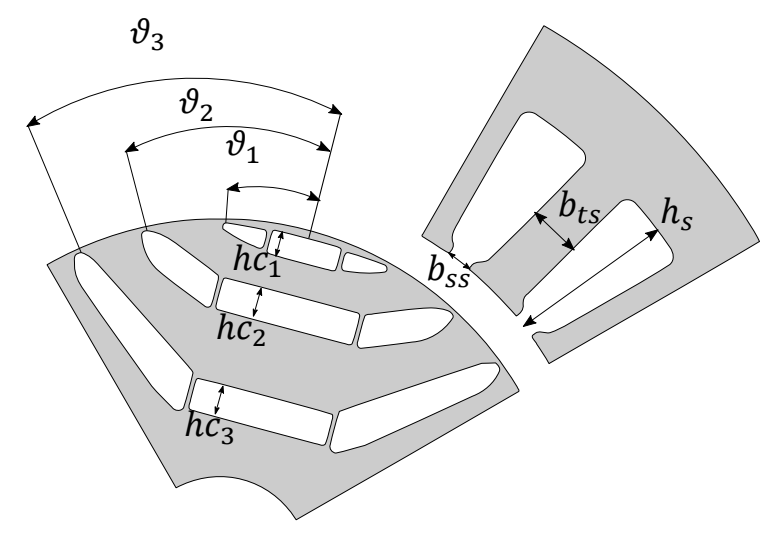

Fig. 6: Sketch of PMaSynRel optimization variables. 
Table IV. Input variables range

\begin{tabular}{cccc}
\hline \hline \multirow{2}{*}{ Symbol } & Parameter & \multicolumn{2}{c}{ Boundaries } \\
\cline { 3 - 4 } & & Lower & Upper \\
\hline$\vartheta_{b 1}$ & Flux barrier angle 1 & $13^{\circ}$ & $16^{\circ}$ \\
$\vartheta_{b 2}$ & Flux barrier angle 2 & $25^{\circ}$ & $28^{\circ}$ \\
$\vartheta_{b 3}$ & Flux barrier angle 3 & $38^{\circ}$ & $40^{\circ}$ \\
$k_{\text {air }}$ & Insulation ratio & 0.35 & 0.45 \\
$h_{s}$ & Slot height & $10 \mathrm{~mm}$ & $18 \mathrm{~mm}$ \\
$b_{s s}$ & Slot opening & $1 \mathrm{~mm}$ & $3.5 \mathrm{~mm}$ \\
$b_{t s}$ & Tooth width & $3.5 \mathrm{~mm}$ & $6 \mathrm{~mm}$ \\
\hline \hline
\end{tabular}

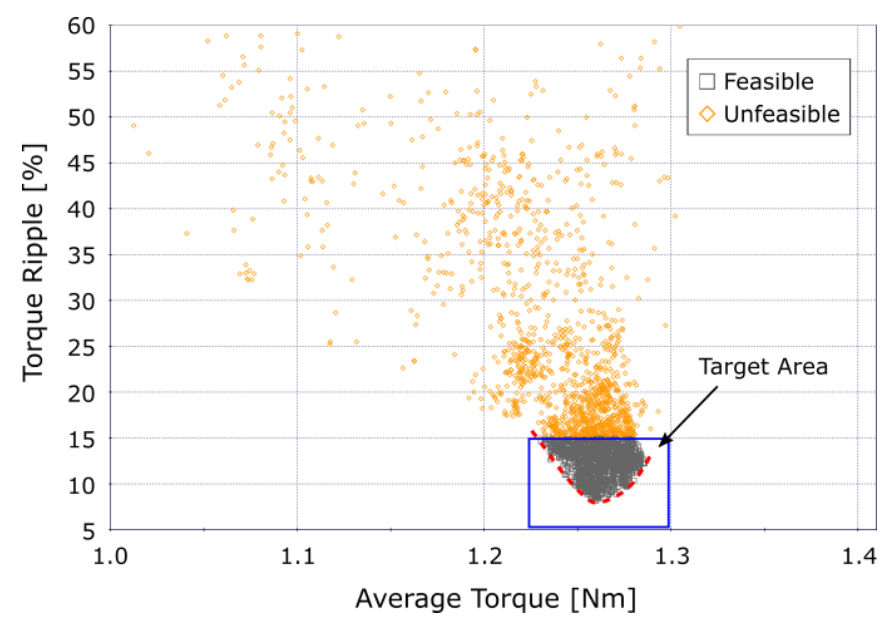

Fig. 7: Pareto front for average torque and torque ripple.

The optimisation results are presented in Fig. 7. Among all the solutions, only $57 \%$ is considered feasible, which means they are respecting the torque and torque ripple design constraints and requirements. These 1368 results are highlighted within the target area confined by a torque ripple below 15\% and the resultant Pareto front (dashed line), where its minimum is $7.25 \%$. The average torque ranges from $1.23 \mathrm{Nm}$ to $1.28 \mathrm{Nm}$, satisfying the requirements. To select the optimal design for this work, the sensitivity analysis criteria described in detail in [18] is implemented.

\begin{tabular}{ccc}
\multicolumn{3}{c}{ Table V. Selected optimal solution. } \\
\hline \hline Symbol & Parameter & Quantity \\
\hline$\vartheta_{b 1}$ & Flux barrier angle 1 & $14.3^{\circ}$ \\
$\vartheta_{b 2}$ & Flux barrier angle 2 & $27.1^{\circ}$ \\
$\vartheta_{b 3}$ & Flux barrier angle 3 & $38.7^{\circ}$ \\
$k_{a i r}$ & Insulation ratio & 0.365 \\
$h_{s}$ & Slot height & $14.5 \mathrm{~mm}$ \\
$b_{s s}$ & Slot opening & $1.85 \mathrm{~mm}$ \\
$b_{t s}$ & Tooth width & $4.58 \mathrm{~mm}$ \\
\hline \hline
\end{tabular}

As the average torque constraint is satisfied, and the parameter variation of the feasible solution is moving within a limited geometrical space, the variables considered for the sensitivity analysis are the flux barrier angles $\left(\vartheta_{b l}, \vartheta_{b 2}\right.$ and $\left.\vartheta_{b 3}\right)$.
The solution presenting the lowest torque ripple sensitivity and with minimum torque ripple is the one reported in Table V. This machine presents a ripple that it is slightly higher with respect to the absolute minimum, $7.9 \%$ against $7.25 \%(+0.65 \%)$, and it is considered acceptable and more robust to the parameter's variation. The stator and rotor laminations of the electrical machine prototyped are shown in Fig. 8.

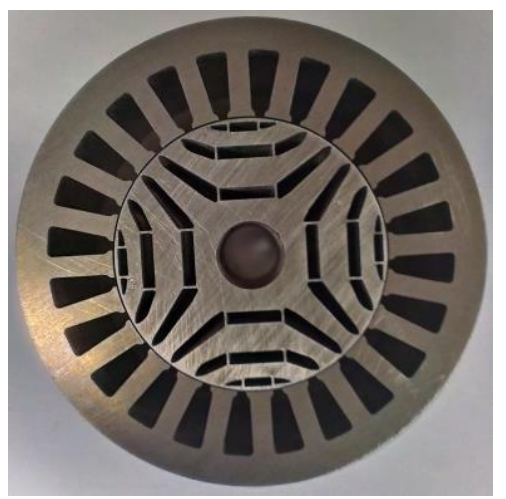

Fig. 8: Photo of stator and rotor cross sections of the prototype, characterised by three flux barriers per pole with central rotor slots to insert the ferrite permanent magnets.

In literature, many works have presented torque ripple reduction strategies. It has been shown that a reduction of the torque ripple can be achieved by uniformly distributing the flux barrier ends along the air gap [29]. An evolution of the above work, extending the rule to odd or even not integer rotor slot numbers per pole pairs, is introduced in [30] and [31]. However, as the torque ripple is very sensitive to the flux barrier ends, other works have shown that with a small variation of a flux barrier angle, by a fraction of an angle, the torque oscillation can significantly change [32]. This is mainly due to the effect that end barrier angles have on the torque ripple harmonics of different order [33]. The results from the optimisation presented in this paper, as reported in Table $\mathrm{V}$, are showing that the flux barrier angles are not equally distributed along the rotor periphery, and represent the solution with the best torque ripple for this specific PMaSynRel motor design.

\section{Cost analysis}

A simple cost analysis is carried out with the purpose of qualitatively compare different motors with the same overall dimensions. The cost of a motor is function of many variable factors, such as manufacturing and assembling processes of the different components, price of the raw materials (which is very volatile), of the processing costs and a number of other fixed and variable costs [34]. Four motors are considered in the following comparison: SCIM with copper and aluminium bars, a SynRel rotor, a PMaSynRel with ferrite magnets. The SCIM is a 2-pole three-phase machine with 24 slots and 32 rotor slots. While both SynRel and PMaSynRel have a 24 slots 4 pole configuration.

With the assumption that all four motors have the same stator geometry, distributed winding and that all the non-active components, such as shaft, bearings and end caps, are the same, only the estimation of the rotor cost is presented in this section. The analysis is considering the raw materials only, as the 
processing cost of cutting and stacking laminations, insertion of PMs (in PMaSynRel) and die-casting (in SCIM) of the rotor bars cannot be accounted for. A non-oriented electrical steel grade is considered (M470-35A) in accordance with European Standard EN 10106 [35]. The reference values used for the mass density of the rotor materials are: $7650 \mathrm{~kg} / \mathrm{m}^{3}$ for the rotor laminations, $8900 \mathrm{~kg} / \mathrm{m}^{3}$ for the copper bars, $2950 \mathrm{~kg} / \mathrm{m}^{3}$ for the aluminium bars and $4800 \mathrm{~kg} / \mathrm{m}^{3}$ for the ferrite PMs. From the volume calculation of the different rotor components and the mass density, the weight can be determined. In Table VI, both weight and cost of the individual components are reported. For the SCIM, the short circuit rings on both sides are also considered, while the SynRel and PMaSynRel do not have any overhanging part. Despite the challenge of defining a specific cost for each raw material, the reference values used for this cost estimation exercise have been defined as: $1.67 \$ / \mathrm{kg}$ for the ferromagnetic steel, $9.23 \$ / \mathrm{kg}$ for the copper bars, $4.55 \$ / \mathrm{kg}$ for the aluminium bars and $3.28 \$ / \mathrm{kg}$ for the ferrite PMs.

These have been considered averaging three different specific costs provided by manufacturers. It is important to highlight that these specific costs will vary depending on the manufacturing and assembling processes for each individual rotor components, as well as depending on the market price.

\begin{tabular}{|c|c|c|c|c|}
\hline \multicolumn{5}{|c|}{ Weight $[\mathrm{kg}]$} \\
\hline \multirow[t]{2}{*}{ Component } & \multicolumn{4}{|c|}{ Rotor type } \\
\hline & $\begin{array}{c}\text { SCIM } \\
(\mathrm{Cu})\end{array}$ & $\begin{array}{c}\text { SCIM } \\
(\mathrm{Al})\end{array}$ & SynRel & PMaSynRel \\
\hline Rotor lam. & 0.701 & 0.701 & 0.679 & 0.679 \\
\hline Cu bars & 0.673 & - & - & - \\
\hline Al bars & - & 0.278 & - & - \\
\hline Ferrite PMs & - & - & - & 0.058 \\
\hline Total weight $\mathrm{kg}$ & 1.374 & 0.979 & 0.679 & 0.737 \\
\hline \multicolumn{5}{|c|}{ Cost [\$] } \\
\hline \multirow[t]{2}{*}{ Component } & \multicolumn{4}{|c|}{ Rotor type } \\
\hline & $\begin{array}{c}\text { SCIM } \\
(\mathrm{Cu})\end{array}$ & $\begin{array}{c}\text { SCIM } \\
\text { (Al) }\end{array}$ & SynRel & PMaSynRel \\
\hline Rotor lam. & 1.17 & 1.17 & 1.14 & 1.14 \\
\hline Cu bars & 6.22 & - & - & - \\
\hline Al bars & - & 1.27 & - & - \\
\hline Ferrite PMs & - & - & - & 2.41 \\
\hline Rotor cost $\$$ & 7.39 & 2.44 & 1.14 & 3.55 \\
\hline
\end{tabular}

The analysis is showing that the rotor with copper bars is the most expensive, while the SynRel rotor the cheapest, given that there are no "excitation circuits". The PMaSynRel rotor is about 3 times more expensive than the SynRel one, because of the additional cost of the ferrite PMs, and about $31 \%$ higher with respect to the rotor with aluminium bars. This comparison, however, is not conclusive, as it represents only the rotor cost considering the raw materials, without accounting for manufacturing processes and volumes.

\section{MACHINE ANALYSIS AND CHARACTERIZATION}

The best PMaSynRel geometry obtained from the optimisation process was analysed in terms of flux and inductance profiles, by means of FE simulations. Using these results, the magnetic model of the motor was built to evaluate the performance of the machine. The magnetic model in $d-q$ reference frame was chosen following the SynRel conventions as shown in Fig. 2. The $d$-axis is aligned with the maximum permeance direction. Consequently, the PM flux linkage is aligned to the q-axis direction. The motor parameters were determined by post processing the results of the FE analysis. Fig. 9 reports the magnetic flux-current and inductance-current characteristics. The separation of the flux curves is due to the current component on the other axis, this effect is caused by the cross-saturation. The simplest way of taking into account the cross saturation, is to store the magnetic model of the machine into two bi-dimensional look-up tables representing $\lambda_{d}=f\left(i_{d}, i_{q}\right)$ and $\lambda_{q}=f\left(i_{d}, i_{q}\right)$.
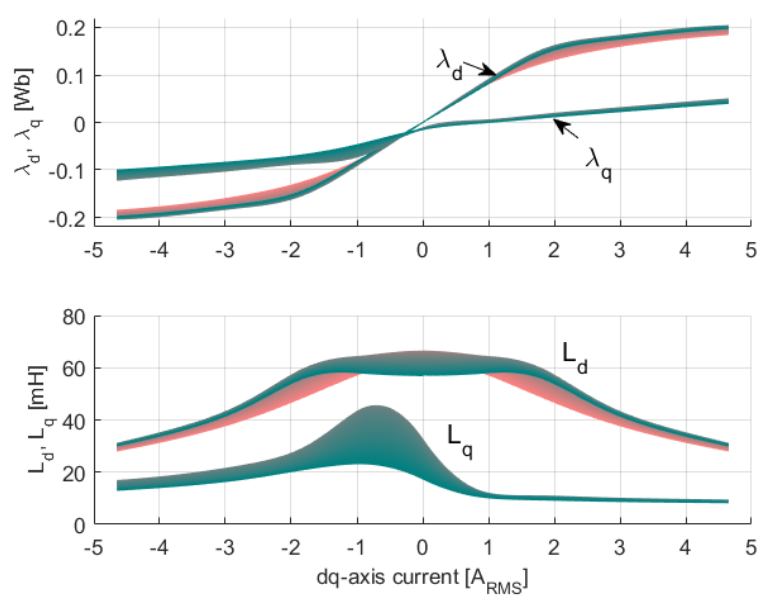

Fig. 9: Magnetic flux-current and inductance-current characteristics computed through FE simulations.

The current space vector trajectory was evaluated according to the Maximum Torque Per Ampere (MTPA) locus and Flux Weakening (FW) up to the maximum speed (16000 rpm). This was created using the aforementioned look up tables to find $d-$ and $q-$ axis flux linkages and the magnetic model was used to find the torque, allowing to identify the optimised trajectory on the $i_{d}-i_{q}$ space.

Based on the magnetic model, the torque speed maps are derived for various machine characteristics. The iron losses were calculated using the Steinmetz method [36]. Traditionally iron losses are divided in two parts: hysteresis losses that varies linearly with the frequency and eddy current losses that varies with the square of the frequency (6). In (6) $P_{h}$ stands for hysteresis loss component, $P_{e}$ is the eddy current loss component, while $C_{h}$ and $C_{e}$ are the material specific hysteresis and eddy current losses coefficients and $\mathrm{B}$ is the flux density of the considered core region.

$$
P_{\text {iron }}=P_{h}+P_{e}=C_{h} \omega B^{2}+C_{e} \omega^{2} B^{2}
$$

The copper losses in general are proportional to product of resistance and square of the current. Whereas the resistance varies with respect to the frequency due to the skin effect (7) [37]. 

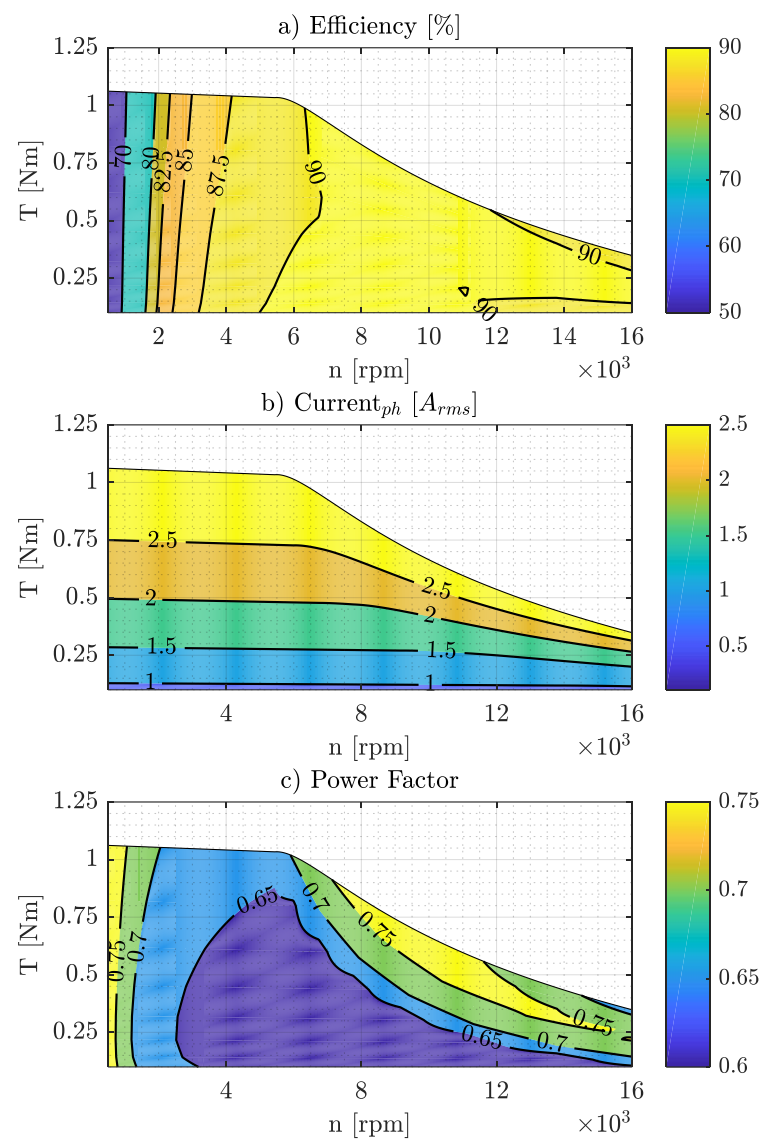

Fig. 10: Torque speed maps derived from FE simulations.

$$
R_{A C}=K_{A C} R_{D C}
$$

Where $R_{D C}$ is the winding DC resistance, $R_{A C}$ is the total effective resistance incorporating the AC loss components. $K_{A C}$ is the AC copper loss coefficient, which depends on the frequency and the winding configuration, it can be calculated by means of FEA as reported in [37], [38].

As shown in Fig. 10, the rated power is achieved at $I_{p h} \sim 3 \mathrm{~A}_{\mathrm{rms}}$. Whereas the power factor and efficiency at rated conditions are PF 0.71 and $\eta \sim 85 \%$. As can be observed the machine is capable to operate for a wider speed ranges, whereas the efficiency margin is above $85 \%$. The iron losses were considered using the Steinmetz empirical equation based on the eddy current and hysteresis losses coefficients of the iron grade M470-35A. The bearings friction losses were calculated according to the manufacturer's datasheet.

\section{EXPERIMENTAL VALIDATION}

\section{A. PMaSynRel Control Scheme:}

The operating region of the PMaSynRel motor is determined by the voltage ellipse and current circle, as shown in Fig. 11. In such $d$ - $q$-axis current plane, the current constraint defines a circle whose center is the origin of the plane.

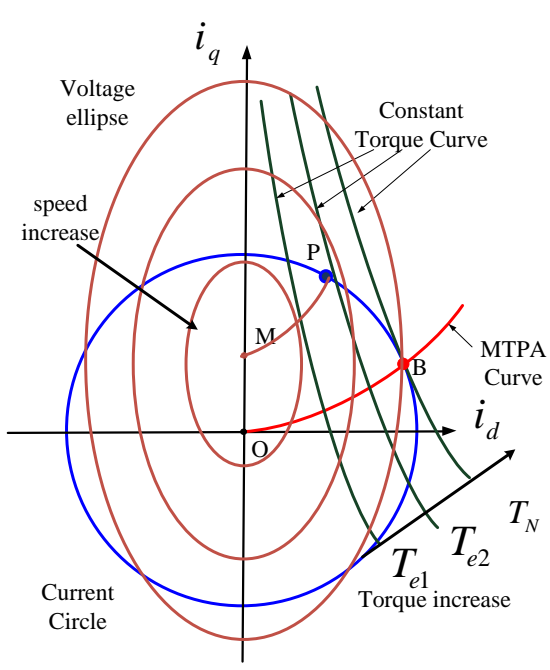

Fig. 11: current operating trajectory in dq-axis current plane.

The voltage constraint defines a family of ellipses, centered in the point $\left(0, \overline{\lambda_{f}} / L_{\mathrm{q}}\right)$, whose major-to-minor axis ratio is equal to the saliency ratio, and the torque equation defines a family of hyperbolas. Below the base speed, the motor is controlled by MTPA (Maximum Torque-per-Ampere) curve OB strategy [39]. With speed increasing, the induced electro motive force (EMF) increases as well. When the EMF is reaching the maximum DC-link voltage utilization, in order to increase the speed, the operating regions need to be extended from constanttorque to constant-power along curve BP. Therefore, the implementation of a field-weakening FW control strategy is needed. The novel aspect of this design is the implementation of a Newton-Raphson-Based Searching Method for improving the control accuracy for optimal current reference, which is described in detail in [28].

In order to validate the proposed PMaSynRel machine designed and optimised in Sec. II, with 24 slots 4 poles, has been prototyped and tested on two different test rigs.

The first is used to validate the torque capability of the machine and estimate the efficiency over the operating current range. The second is used to characterise the machine's torque over the $i_{d}-i_{q}$ plane and to measure the torque ripple.

\section{B. Torque and efficiency capability}

The rig consists of a Magtrol setup made of a dynamometer, hysteresis brake and a torque sensor, as shown in Fig. 12, with its main components. The Magtrol controller has a minimum torque resolution of $0.001 \mathrm{Nm}$. The motor is driven by a smart
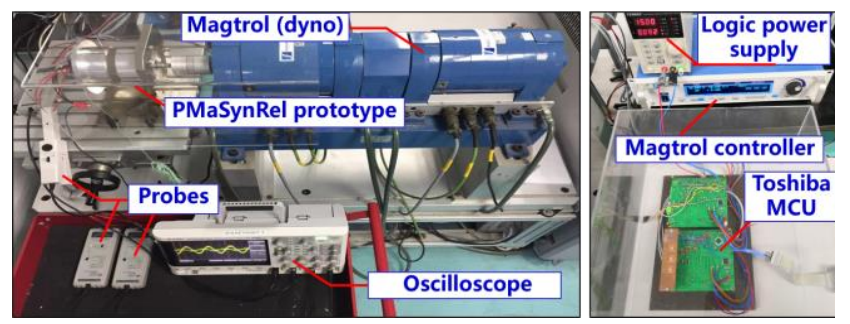

Fig. 12. Experimental test set-up. 
a)

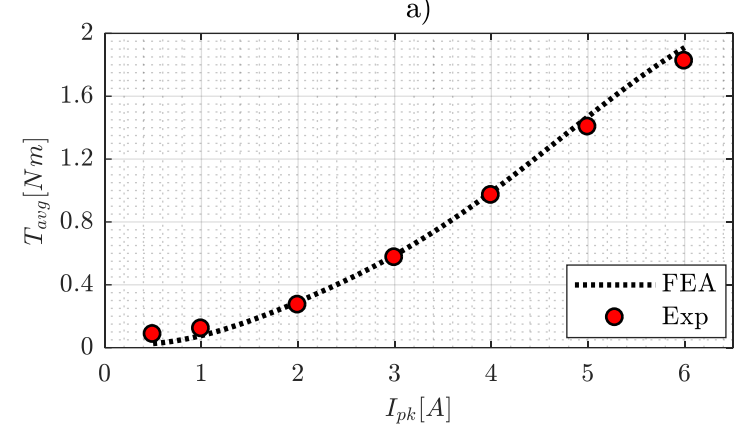

b)

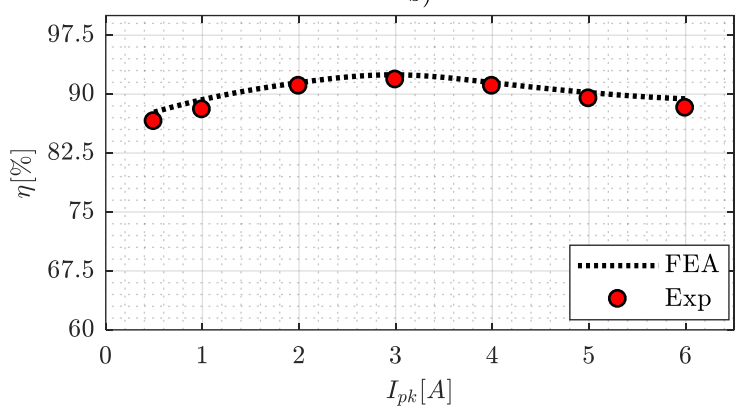

Fig. 13: Experimental and FEA comparison a) torque-current characteristics b) efficiency.

power module STK5Q4U362J and controlled by the 32-bit Toshiba TMPM374FWUG microcontroller.

The latter is a 32-bit fixed-point microprocessor embedded with an ARM Cortex-M3 core and is utilised as a low cost solution for household appliances. The rotor position is measured by means of an encoder with 4096 pulses per revolution.

The experimental results have been captured at different phase current values from $0.5 \mathrm{~A}_{\mathrm{pk}}$ to $6 \mathrm{~A}_{\mathrm{pk}}$ at rated speed 5200 rpm. In Fig. 13 the comparisons between the FEA results with the measurements data are shown: a) torque; b) efficiency. It can be observed that at lower current values, below $1 \mathrm{~A}$, there is some error probably due to a different saturation of the manufactured core and iron ribs. However, for currents above $1 \mathrm{~A}_{\mathrm{pk}}$ the experimental measurements are matching very well the predicted torque-current characteristic predicted via FEA.

Similar behavior is shown for the efficiency, shown in Fig. $13 \mathrm{~b}$ ), with an overestimation of maximum $0.6 \%$ in the FE simulated results compared to experimental data, which can be considered a good match given the small size of the motor.

In fact, in the current range of operation, the efficiency values are varying from $86.2 \%$ to $91.8 \%$. These results prove that the usage of the PMaSynRel machine can significantly boost the efficiency with respect to the state-of-the-art solutions. For example, IMs with the same frame size configuration, reported in [9] and [11], designed for household appliances present lower rated efficiency, $52 \%$ and $\sim 60 \%$, respectively. In conclusion, from the results presented in this subsection, the proposed solution is able to deliver the torque required at the rated speed meeting the initial target values summarized in Table I. The motor torque characteristics over the $i_{d}-i_{q}$-plane is shown in Fig. 14.

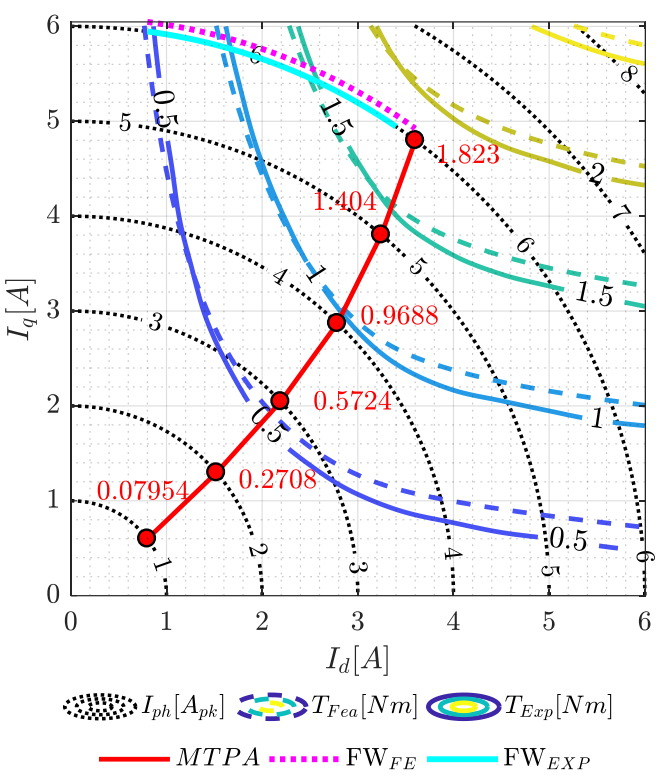

Fig. 14: Torque-current characteristics comparison: (top) finite element results; (bottom) experimental measurements.

The PMaSynRel is driven by a master motor in speed mode at 5000rpm, the torque is acquired via the torque transducer by applying different $d$ - $q$-axis current setpoints to cover the $d$ - $q$ axis current plane [39].

The results shown in Fig. 14 indicate that the experimental results (solid lines) and FE simulations (dashed lines) are in good agreement, Flux Weakening (FW) trajectories are highlighted for both FE simulated and experimentally obtained data. Some difference occurs due to a slightly different saturation behaviour of the manufactured machine with respect to FE model. The measurements have been carried out for a wider range of currents pushing the drive to its maximum current limit for short periods of time in order to avoid the machine overheating. The MTPA line is highlighted in red, for specific sets of $i_{d}-i_{q}$, searching for the current angles that are minimising the copper loss.

\section{Torque ripple validation}

The machine torque ripple has been characterised on a custom test rig presented in Fig. 15, described in detail in [19]. The tests are carried out at low speed to capture the high frequency nature of the torque oscillations. The motor M1 under test is connected through a torquemeter to a master motor (dyno). A non-reversible gear box is reducing the speed by a 1:59 ratio, as shown in Fig. 15. The control algorithm is implemented on a dSpace 1104 platform. In Fig. 16 the torque waveform are reported as a function of the rotor position, for two different phase currents, $I_{p h}=4 \mathrm{~A}$ and $4.6 \mathrm{~A}$, respectively. For both measurements the current angle selected is the one at the MTPA, corresponding to 47 and 49.5 electrical degrees, respectively. 


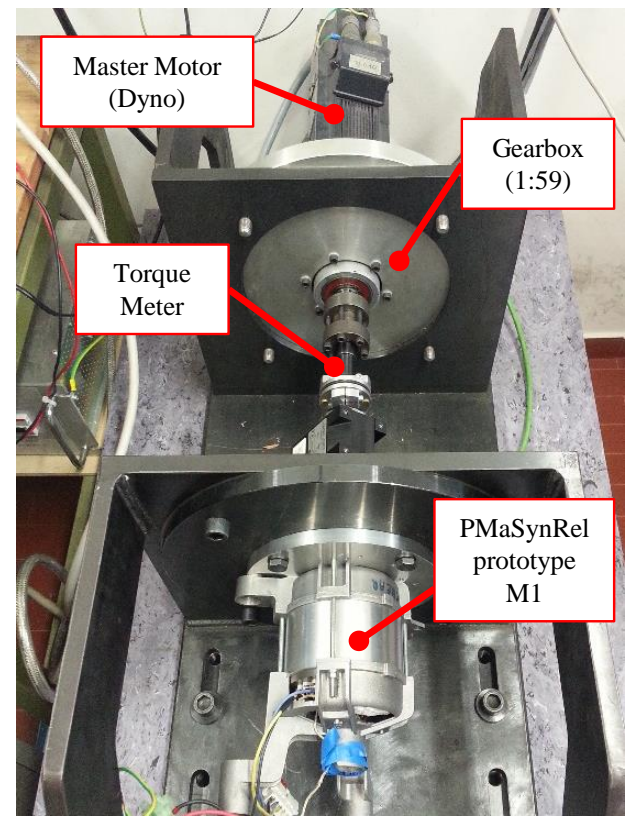

Fig. 15: Torque ripple experimental test rig.
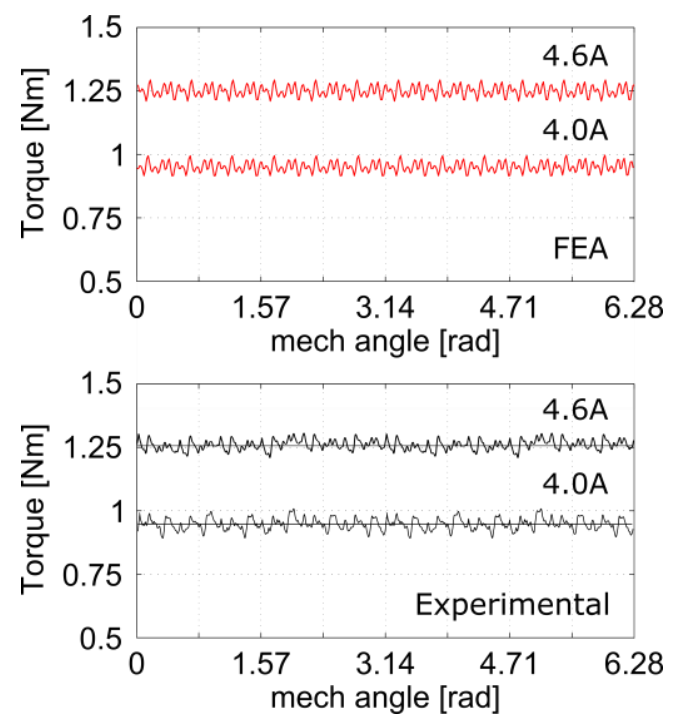

Fig. 16: Torque ripple comparison for two operating currents 4A and 4.6A: (top) finite element results; (bottom) experimental measurements.

The experimental measurements show a good agreement with the FEA results and the torque peaks are well represented. The current waveforms are presented on Fig. 17. These were corresponding to produced torque values of a) $0.97 \mathrm{Nm}$ and b) $1.25 \mathrm{Nm}$, respectively. Based on these results, the following considerations can be derived: 1) The torque values from FE analysis are slightly higher than the measured ones for both current values. 2) The torque ripple waveforms instead have an opposite behaviour, where the experimental results are $1.1 \%$, and $1.5 \%$ higher with respect to the FE calculated ones, for 4 and $4.6 \mathrm{~A}$, respectively. This is justified because of the additional harmonics added by the converter supply to electromagnetic ripple of the machine. a)

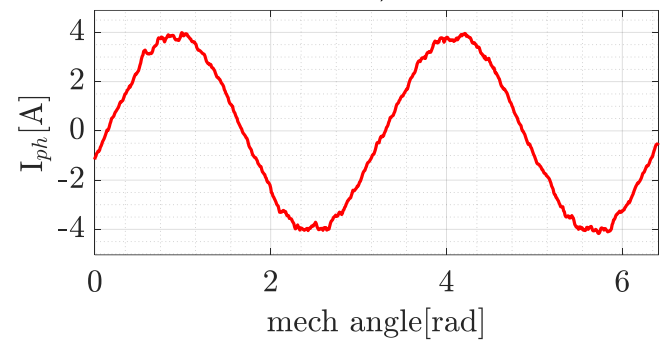

b)

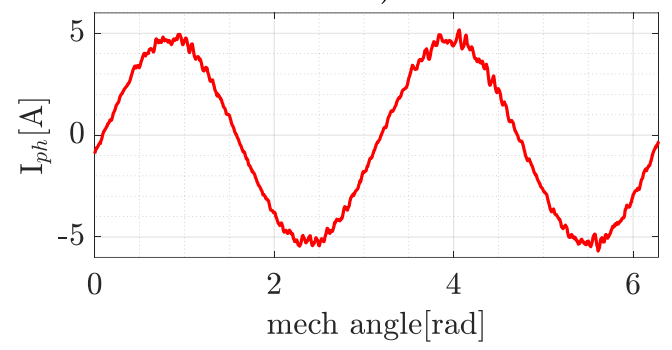

Fig. 17: Current waveforms, a) $\mathrm{I}_{\mathrm{pk}}=4 \mathrm{~A}$, b) $\mathrm{I}_{\mathrm{pk}}=4.6 \mathrm{~A}$.

Overall, the torque ripple simulated and measured are still within an acceptable design range. The summary of the results described is reported in

Table VII.

Table VII. Summary of the torque evaluation

\begin{tabular}{ccccc}
\hline \hline$I_{p k}$ & $\mathrm{~T}_{\mathrm{FEA}}(\mathrm{Nm})$ & $\mathrm{T}_{\mathrm{EXP}}(\mathrm{Nm})$ & $\mathrm{T} \Delta_{\mathrm{FEA}}(\%)$ & $\mathrm{T} \Delta_{\mathrm{EXP}}(\%)$ \\
\hline $4.0 \mathrm{~A}$ & 0.968 & 0.963 & 9.1 & 10.2 \\
$4.6 \mathrm{~A}$ & 1.253 & 1.249 & 8.2 & 9.7 \\
\hline$I_{p k}$ & \multicolumn{2}{c}{ Error $\mathrm{T}_{\mathrm{AVG}}(\%)$} & \multicolumn{2}{c}{ Difference $(\%)$} \\
\hline $4.0 \mathrm{~A}$ & \multicolumn{2}{c}{0.319} & \multicolumn{2}{c}{$+1.1 \%$} \\
$4.6 \mathrm{~A}$ & \multicolumn{2}{c}{0.516} & \multicolumn{2}{c}{$+1.5 \%$} \\
\hline
\end{tabular}

\section{CONCLUSIONS}

This paper presents the design of a PMaSynRel machine optimised of a specific electromechanical characteristic, suitable for household appliances. Starting from a preliminary analytical design, the machine is then optimised to increase the torque capability, maintaining the same current loading, minimising the losses per volume. The torque oscillations have also been minimised given the intrinsic high values that these types of motors present. The optimal solution has been selected and a prototype of 4 poles PMaSynRel motor manufactured and assembled. As the application is high volume low value, thus the overall drive cost is of paramount importance, a control algorithm has been implemented on a commercial 32-bit Toshiba TMPM375 microcontroller. The drive has been tested on two experimental platforms. The torque capability is satisfying the design requirements and can exceed the rated torque value by $30 \%$, to allow for transient overload operations. An excellent efficiency is achieved compared to the conventional SCIMs with similar frame size, making the PMaSynRel drive a good candidate for white goods appliances. 


\section{REFERENCES:}

C. M. Donaghy Spargo, "Synchronous Reluctance Motor Technology: Industrial Opportunities, Challenges and Future Direction," Eng. Technol. Ref., vol. 44, no. May, pp. 1-15, 2016, doi: http://dx.doi.org/10.1049/etr.2015.0044.

[2] S. Yamamoto, H. Hirahara, J. B. Adawey, T. Ara, and K. Matsuse, "Maximum efficiency drives of synchronous reluctance motors by a novel loss minimization controller with inductance estimator," IEEE Trans. Ind. Appl., vol. 49, no. 6, pp. 2543-2551, 2013.

[3] B. C. Mecrow and A. G. Jack, "Efficiency trends in electric machines and drives," Energy Policy, vol. 36, no. 12, pp. 4336-4341, 2008

[4] A. T. De Almeida, F. J. T. E. Ferreira, and G. Baoming, "Beyond induction motors-Technology trends to move up efficiency," IEEE Trans. Ind. Appl., vol. 50, no. 3, pp. 2103-2114, 2013.

[5] A. T. De Almeida, F. J. T. E. Ferreira, and A. Quintino, "Technical and economical considerations on super high-efficiency three-phase motors," in 48th IEEE Industrial $\backslash \&$ Commercial Power Systems Conference, 2012, pp. 1-13.

[6] R. N. Tuncay, M. Yilmaz, and C. Onculoglu, "The design methodology to develop new-generation universal-motors for vacuum cleaners," in IEMDC 2001. IEEE International Electric Machines and Drives Conference (Cat. No. 01EX485), 2001, pp. 926-930.

[7] G. Papa, B. Korousic-Seljak, B. Benedicic, and T. Kmecl, "Universal motor efficiency improvement using evolutionary optimization," IEEE Trans. Ind. Electron., vol. 50, no. 3, pp. 602-611, 2003.

[8] J.-Y. Lim, Y.-C. Jung, S.-Y. Kim, and J.-C. Kim, "Single phase switched reluctance motor for vacuum cleaner," in ISIE 2001. 2001 IEEE International Symposium on Industrial Electronics Proceedings (Cat. No. 01TH8570), 2001, vol. 2, pp. 1393-1400.

[9] H. S. Rajamani and R. A. McMahon, "Induction motor drives for domestic appliances," IEEE Ind. Appl. Mag., vol. 3, no. 3, pp. 21-26, 1997.

[10] E. Armando, P. Guglielmi, M. Pastorelli, G. Pellegrino, and A. Vagati, "Performance of IPM-PMASR Motors with Ferrite Injection for Home Appliance Washing Machine," in 2008 IEEE Industry Applications Society Annual Meeting, 2008, pp. 1-6.

[11] J. S. Moghani and M. Heidari, "High efficient low cost induction motor drive for residential applications," in International Symposium on Power Electronics, Electrical Drives, Automation and Motion, 2006. SPEEDAM 2006., 2006, pp. 1399-1402.

[12] G. Brown, "Developing synchronous reluctance motors for variable speed operation," in 6th IET International Conference on Power Electronics, Machines and Drives (PEMD 2012), 2012, pp. 1-6.

[13] R. R. Moghaddam and F. Gyllensten, "Novel high-performance SynRM design method: An easy approach for a complicated rotor topology," IEEE Trans. Ind. Electron., vol. 61, no. 9, pp. 5058-5065, 2014, doi: 10.1109/TIE.2013.2271601.

[14] M. Ferrari, N. Bianchi, A. Doria, and E. Fornasiero, "Design of synchronous reluctance motor for hybrid electric vehicles," IEEE Trans. Ind. Appl., vol. 51, no. 4, pp. 3030-3040, 2015.

[15] H. Cai, B. Guan, and L. Xu, "Low-cost ferrite PM-assisted synchronous reluctance machine for electric vehicles," IEEE Trans. Ind. Electron., vol. 61, no. 10, pp. 5741-5748, 2014.

[16] G. Pellegrino, T. M. Jahns, N. Bianchi, W. L. Soong, and F. Cupertino, The rediscovery of synchronous reluctance and ferrite permanent magnet motors: tutorial course notes. Springer, 2016.

[17] M. Morandin, S. Bolognani, R. Petrella, A. Pevere, and S. Calligaro, "Mild-hybrid traction system based on a bidirectional half-bridge interleaved converter and a three-level active NPC inverter-fed PMSM," in 2012 Twenty-Seventh Annual IEEE Applied Power Electronics Conference and Exposition (APEC), 2012, pp. 16441651.

[18] M. Degano, E. Carraro, and N. Bianchi, "Selection Criteria and Robust Optimization of a Traction PM Assisted Synchronous Reluctance Motor," vol. 9994, no. c, 2015, doi: 10.1109/TIA.2015.2443091.

[19] N. Bianchi, E. Fornasiero, M. Ferrari, and M. Castiello, "Experimental Comparison of PM-Assisted Synchronous Reluctance Motors," vol. 52, no. 1, pp. 163-171, 2016.

[20] Y. Bao et al., "A Novel Concept of Ribless Synchronous Reluctance Motor for Enhanced Torque Capability," IEEE Trans. Ind. Electron., vol. 67, no. 4, pp. 2553-2563, 2020, doi: 10.1109/TIE.2019.2914616.
O. Payza, Y. Demir, and M. Aydin, "Investigation of Losses for a
Concentrated Winding High-Speed Permanent Magnet-Assisted Synchronous Reluctance Motor for Washing Machine Application," IEEE Trans. Magn., vol. 54, no. 11, pp. 1-5, 2018.

[22] N. Bianchi, S. Bolognani, E. Carraro, M. Castiello, and E. Fornasiero, "Electric vehicle traction based on synchronous reluctance motors," IEEE Trans. Ind. Appl., vol. 52, no. 6, pp. 4762-4769, 2016.

[23] B. Z. Q. Zhu and D. Howe, "Electrical Machines and Drives for Electric , Hybrid , and Fuel Cell Vehicles," vol. 95, no. 4, 2007.

[24] M. Murataliyev, M. Degano, and M. Galea, "A Novel Sizing Approach for Synchronous Reluctance Machines," IEEE Trans. Ind. Electron., vol. 0046, no. 2, 2020, doi: 10.1109/TIE.2020.2975461.

[25] B. Gaussens, E. Hoang, O. De La Barrière, J. Saint-Michel, M. Lecrivain, and M. Gabsi, "Analytical approach for air-gap modeling of field-excited flux-switching machine: No-load operation," IEEE Trans. Magn., vol. 48, no. 9, pp. 2505-2517, 2012, doi: 10.1109/TMAG.2012.2196706.

[26] M. Palmieri, M. Perta, and F. Cupertino, "Design of a 50.000-r/min synchronous reluctance machine for an aeronautic diesel engine compressor," IEEE Trans. Ind. Appl., vol. 52, no. 5, pp. 3831-3838, 2016.

[27] M. Di Nardo, G. Lo Calzo, M. Galea, and C. Gerada, "Design optimization of a high-speed synchronous reluctance machine," IEEE Trans. Ind. Appl., vol. 54, no. 1, pp. 233-243, 2017.

[28] M. Barcaro, N. Bianchi, and F. Magnussen, "Remarks on torque estimation accuracy in fractional-slot permanent-magnet motors," IEEE Trans. Ind. Electron., vol. 59, no. 6, pp. 2565-2572, 2011.

[29] A. Vagati, M. Pastorelli, G. Francheschini, and S. C. Petrache, "Design of low-torque-ripple synchronous reluctance motors," IEEE Trans. Ind. Appl., vol. 34, no. 4, pp. 758-765, 1998.

[30] R. R. Moghaddam, "Rotor for a synchronous reluctance machine." Google Patents, 2014.

[31] R. Rajabi Moghaddam, "Synchronous reluctance machine (SynRM) in variable speed drives (VSD) applications," KTH Royal Institute of Technology, 2011.

[32] N. Bianchi, M. Degano, and E. Fornasiero, "Sensitivity analysis of torque ripple reduction of synchronous reluctance and interior PM motors," IEEE Trans. Ind. Appl., vol. 51, no. 1, pp. 187-195, 2015, doi: 10.1109/TIA.2014.2327143.

[33] N. Bianchi, S. Bolognani, D. Bon, and M. D. Pré, "Rotor flux-barrier design for torque ripple reduction in synchronous reluctance and PMassisted synchronous reluctance motors," IEEE Trans. Ind. Appl., vol. 45, no. 3, pp. 921-928, 2009, doi: 10.1109/TIA.2009.2018960.

[34] G. Novak, J. Kokošar, A. Nagode, and D. S. Petrovič, "Core-loss prediction for non-oriented electrical steels based on the Steinmetz equation using fixed coefficients with a wide frequency range of validity," IEEE Trans. Magn., vol. 51, no. 4, pp. 1-7, 2014.

[35] C. R. N.-O. E. Steel, "Sheet and Strip Delivered in the Fully Processed State," SIST Stand. EN, vol. 10106, p. 2014, 2014.

[36] D. M. Ionel, M. Popescu, S. J. Dellinger, T. J. E. Miller, R. J. Heideman, and M. I. McGilp, "On the variation with flux and frequency of the core loss coefficients in electrical machines," IEEE Trans. Ind. Appl., vol. 42, no. 3, pp. 658-667, 2006, doi: 10.1109/TIA.2006.872941.

[37] P. Mellor, R. Wrobel, and N. Simpson, "AC Losses in High Frequency Electrical Machine Windings formed from Large Section Conductors," no. 2, pp. 5563-5570, 2014.

[38] A. S. Thomas, Z. Q. Zhu, and G. W. Jewell, "Proximity loss study in high speed flux-switching permanent magnet machine," IEEE Trans. Magn., vol. 45, no. 10, pp. 4748-4751, 2009.

[39] S. Wang, M. Degano, J. Kang, A. Galassini, and C. Gerada, "A novel Newton-Raphson-based searching method for the MTPA control of PMaSynRM considering magnetic and cross saturation," in 2018 XIII International Conference on Electrical Machines (ICEM), 2018, pp. $1360-1366$. 


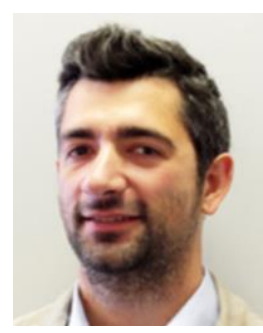

Michele Degano (Member, IEEE) received the Master's degree in electrical engineering from the University of Trieste, Italy, in 2011, and the $\mathrm{Ph} . \mathrm{D}$. degree in industrial engineering from the University of Padova, Italy, in 2015. Between 2014 and 2016, he was a Postdoctoral Researcher at The University of Nottingham, U.K., where he joined the Power Electronics, Machines and Control (PEMC) Research Group. In 2016 he was appointed Assistant Professor in Advanced Electrical Machines, at The University of Nottingham, U.K. He was promoted Associate Professor in 2020. His main research focuses on electrical machines and drives for industrial, automotive, railway and aerospace applications, ranging from small to large power. He is currently the PEMC Director of Industrial Liaison leading research projects for the development of future hybrid electric aerospace platforms and electric transports.

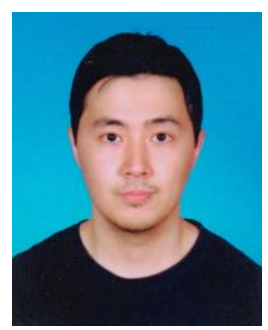

Mukhammed Murataliyev (Member, IEEE) received his Master's degree in electrical engineering from the University of Nottingham, Malaysia in 2016. He received a Ph.D. degree from University of Nottingham China and UK in 2021, with a focus on novel synchronous reluctance motor design and optimization methods. From 2018 - 2020 he was a part time Researcher with the Key Laboratory of More Electric Aircraft Technology of Zhejiang Province. Since 2021, he joined the Power Electronics and Machine Control Group of the University of Nottingham, UK as a Research Fellow. He has been working on several projects for to design of electrical machines for traction, aerospace and industrial applications. His main research interest includes design and modeling of reluctance and permanent magnet machines for industrial and aerospace applications.

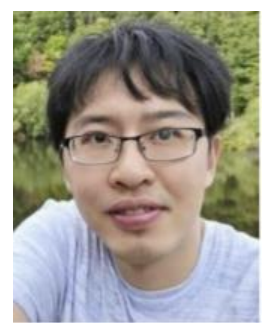

Shuo Wang (Member, IEEE) received the bachelor degree in automation from the Hebei University of Technology in 2011, Tianjin, China, master degree in control science and engineering from Tianjin University in 2014, Tianjin, China, and Ph.D. degree in control science and engineering from Tongji University in 2019, Shanghai, China. From 2017 to 2018, he became a Visiting Researcher with Power Electronics, Machines and Control Group (PEMC Group), University of Nottingham, Nottingham, U.K. He is currently working as a Senior Research Fellow in the University of Nottingham, Ningbo, China. His current research interests include high performance torque control, sensorless control and flux-weakening control used for permanent magnet synchronous machines, synchronous reluctance machines and permanent magnet-assisted synchronous reluctance machines.

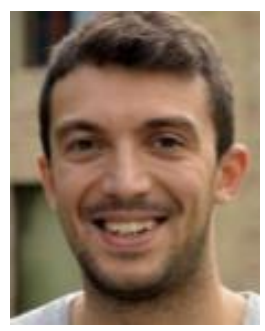

Davide Barater (Member, IEEE) received the master's degree in electronic engineering and the $\mathrm{Ph} . \mathrm{D}$. degree in information technology from the University of Parma, Italy, in 2009 and 2014, respectively. He was an Honorary Scholar with the University of Nottingham, U.K., in 2012, and a Visiting Researcher with the University of Kiel, in 2015. He is currently an Assistant Professor with the Department of Engineering Enzo Ferrari, University of Modena and Reggio Emilia, Italy. He is the author or coauthor of more than 60 international articles. His research interests include power electronics for e-mobility and motor drives. He is the Coordinator of two European Project, such as RAISE, that evaluates the impact of the high voltage gradients, introduced by the fast commutations of new wide bandgap power devices ( $\mathrm{SiC}, \mathrm{GaN}$ ), on the life time of electrical motor insulation systems and AUTO-MEA, that aims to develop electrical motors and drives for next generation of electrical mobility. In particular, novel solutions for windings structures and cooling systems for improved power density, efficiency, and increased frequency operation. Dr. Barater is an Associate Editor of the IEEE TRANSACTIONS ON INDUSTRY APPLICATIONS.

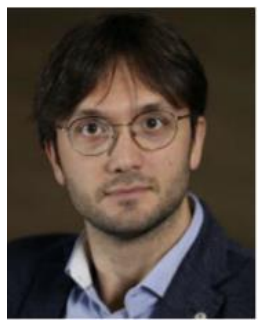

Giampaolo Buticchi (Senior Member, IEEE) received the Master degree in electronic engineering in 2009 and the Ph.D degree in information technologies in 2013 from the University of Parma, Italy. In 2012 he was Visiting Researcher at The University of Nottingham, U.K. Between 2014 and 2017, he was a Postdoctoral Researcher, and Guest Professor at the University of Kiel, Germany. During his stay in Germany, he was awarded with the Von Humboldt Post-Doctoral Fellowship to carry out research related to fault tolerant topologies of smart transformers. He was appointed in 2017 Associate Professor in Electrical Engineering at The University of Nottingham Ningbo China and the Head of Power Electronics of the Nottingham Electrification Center. He was promoted Professor in 2020. His research focuses on power electronics for renewable energy systems, smart transformer fed micro-grids and dc grids for the More Electric Aircraft. Dr. Buticchi is one of the advocates for DC distribution systems and multi-port power electronics onboard the more electric aircraft. He is author/co-author of more than 200 scientific papers and an Associate Editor of the IEEE TRANSACTIONS ON INDUSTRIAL ELECTRONICS, the IEEE TRANSACTIONS ON TRANSPORTATION ELECTRIFICATION and the IEEE Open Journal of the Industrial Electronics Society. He is currently the Chair of the IEEE Industrial Electronics Society Technical Committee on Renewable Energy Systems.

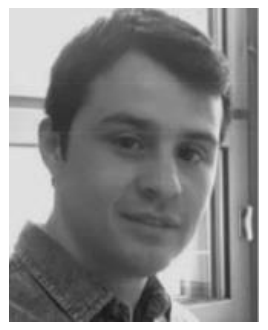

Werner Jara (Member, IEEE) received the B.Sc. degree in electrical engineering from the University of Concepción, Concepción, Chile, in 2010, and the D.Sc. degree from the University of Concepción, Concepción, Chile, and the Lappeenranta University of Technology, Lappeenranta, Finland, both in 2016. He is currently a Lecturer with the Department of Electrical Engineering, Pontificia Universidad Católica de Valparaíso, Valparaíso, Chile. His current research interests include the field of electrical machines and drives, particularly numerical modeling, and design of electromagnetic devices.

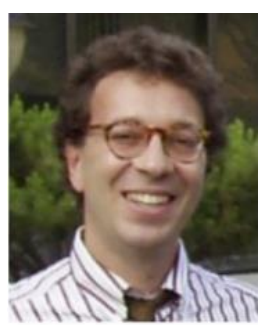

Nicola Bianchi (Fellow, IEEE), received the M.Sc. and Ph.D. degrees in electrical engineering from the University of Padova, Padova, Italy, in 1991 and 1995, respectively. In 1998, he joined the Department of Electrical Engineering, University of Padova, as an Assistant Professor, where since 2005, he has been an Associate Professor in Electrical Machines, Converters, and Drives with the Electric Drive Laboratory, Department of Electrical Engineering. He has authored and coauthored several scientific papers and international books on electrical machines and drives. His research interests include the field of design of electrical machines, particularly for drive applications. Dr. Bianchi was the recipient of five awards for best conference and journal papers. $\mathrm{He}$ is a member of the Electric 
Machines Committee and the Electrical Drives Committee of the IEEE Industry Applications Society. He was a Technical Program Chair for the IEEE Energy Conversion Congress and Exposition in 2014 and is currently an Associate Editor for the IEEE TRANSACTIONS ON INDUSTRY APPLICATIONS.

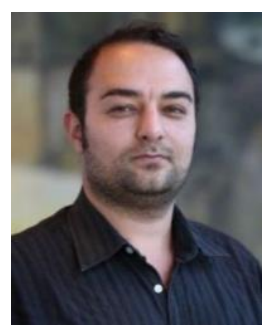

Michael Galea (Senior Member, IEEE, FRAeS) received his $\mathrm{PhD}$ in electrical machines design from the University of Nottingham, UK, where he has also worked as a Research Fellow. $\mathrm{He}$ is currently the Head of School of Aerospace in the University of Nottingham, Ningbo, China, where he is also the Director of Aerospace. He currently lectures in Electrical Drives and in Aerospace Systems Integration and manages a number of diverse projects and programmes related to the more / all electric aircraft, electrified propulsion and associated fields. His main research interests are design, analysis and thermal management of electrical machines and drives (classical and unconventional), the more electric aircraft and electrified and hybrid propulsion. He is a Fellow of the Royal Aeronautical Society and a Senior Member of the IEEE.

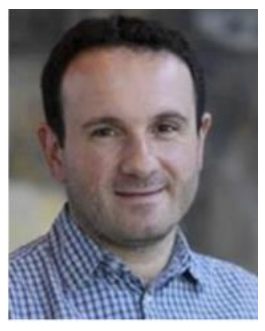

Chris Gerada (Senior Member, IEEE) is an Associate Pro-ViceChancellor for Industrial Strategy and Impact and Professor of Electrical Machines. His principal research interest lies in electromagnetic energy conversion in electrical machines and drives, focusing mainly on transport electrification. He has secured over $£ 20 \mathrm{M}$ of funding through major industrial, European and UK grants and authored more than 350 referred publications. He received the $\mathrm{Ph} . \mathrm{D}$. degree in numerical modelling of electrical machines from The University of Nottingham, Nottingham, U.K., in 2005. He subsequently worked as a Researcher with The University of Nottingham on high-performance electrical drives and on the design and modelling of electromagnetic actuators for aerospace applications. In 2008, he was appointed as a Lecturer in electrical machines; in 2011, as an Associate Professor; and in 2013, as a Professor at The University of Nottingham. He was awarded a Research Chair from the Royal Academy of Engineering in 2013. Prof. Gerada served as an Associate Editor for the IEEE Transactions on Industry Applications and is the past Chair of the IEEE IES Electrical Machines Committee. 